Kuronen, M., P. Lintunen \& T. Nieminen (toim.) 2017. Näkökulmia toisen kielen puheeseen Insights into second language speech. AFinLA-e. Soveltavan kielitieteen tutkimuksia 2017 / n:o 10. 98-117.

\author{
Henna Heinonen \\ Jyväskylä universitet
}

\title{
Begripligheten av finskspråkiga gymnasisters svenska uttal: lyssnarvärderingar
}

\begin{abstract}
The aim of this study is to investigate how comprehensible L1 Finnish speakers' L2 Swedish is considered to be and whether any listener- or speaker-specific background factors relating to the comprehensibility judgements can be found. The research material consists of Swedish read-aloud texts by 21 Finnish-speaking upper secondary school students. Judgements are given by 64 native Swedish-speakers (Finland-Swedish $n=35$, Sweden-Swedish $n=29$ ) using a verbalized scale from 1 to 7 . The study shows that L2 Swedish, pronounced by L1 Finnish speakers, is on average considered to be comprehensible but the listener has to concentrate closely. Both Finland-Swedish and Sweden-Swedish listeners gave similar ratings. Only two background factors correlated with the comprehensibility ratings: the speaker's latest school grade in Swedish had a negative correlation, whereas the speaker's usage of Swedish on his/her spare time correlated positively with the comprehensibility ratings.
\end{abstract}

Keywords: comprehensibility, pronunciation, L2 Swedish

Nyckelord: begriplighet, uttal, svenska som andraspråk 


\section{Inledning}

Begriplighet har varit ett av de viktigaste målen för uttalsinlärningen redan i årtionden (se t.ex. Thorén 2008; GLGY 2003; Abercrombie 1949 citerat i Munro \& Derwing 1995a). Målet är relevant. Ett begripligt uttal är nödvändigt för lyckad kommunikation: det har större betydelse för lyssnarperceptionen än t.ex. grammatisk korrekthet (t.ex. Kjellin 2002; Fayer \& Krasinski 1987). Det som gör uttalets roll avgörande för begripligheten är prosodiska drag såsom satsbetoning, rytm och melodi. De hjälper lyssnaren att uppfatta gränserna mellan orden och fraserna och upptäcka den viktigaste informationen (t.ex. Saito m.fl. 2016; Field 2005; Kjellin 2002; Munro \& Derwing 1995a; Bannert 1984: 211). Uttalet och prosodin har dock förbisetts i den finländska språkundervisningen (Tergujeff 2013; livonen \& Tella 2009), som ändå syftar till ett lättbegripligt uttal (GLGY 2003, 2015). Denna diskrepans gör finskspråkiga talares uttal och dess begriplighet till ett relevant undersökningsobjekt.

Syftet med den här undersökningen är att kartlägga begripligheten av finskspråkiga gymnasisters svenska uttal. Målet är att utreda begriplighetsnivån genom skalbedömning och undersöka hur olika bakgrundsfaktorer hos talare och lyssnare påverkar begriplighetsbedömningarna. Undersökningen besvarar följande forskningsfrågor: 1) Hur begripligt är finskspråkiga gymnasisters svenska uttal? 2) Avviker begriplighetsvärderingarna givna av finlandssvenska lyssnare och sverigesvenska lyssnare från varandra? 3) Finns det några faktorer i lyssnarnas och talarnas bakgrund såsom ålder, kön eller språklig bakgrund, som relaterar till begriplighetsvärderingen?

Enligt läroplanerna har begripligheten stått som mål för muntlig färdighet relativt länge (Opetushallitus 1994). Trots det har finskspråkiga gymnasisters svenska uttal och begriplighet studerats bara i en tidigare undersökning. Uttalet beskrevs likna finlandssvenska och det tänktes inte vålla några problem för begripligheten, som i sin tur ansågs förknippas främst med lexikala faktorer (Hildén 2000). Uttalet och begripligheten värderades av L2-lyssnare, medan L1-lyssnares uppfattning förblev outforskad i studien (Hildén 2000: 245-256).

Talarna i den här undersökningen har studerat svenska i flera år och sålunda antas ett begripligt uttal inte vålla stora problem för dem (jfr Hildén 2000: 246). Samtidigt har språkundervisningen varit inriktad på skriftliga färdigheter redan länge, och därför kan talarnas färdigheter i uttal vara sämre än deras språkfärdighet i övrigt. Den andra forskningsfrågan gäller variantens inverkan på begripligheten. Svenskstudierna i gymnasium syftar till interaktion i Norden (GLGY 2015), vilket innebär kommunikation med både finlandssvenska och sverigesvenska talare. Då lyssnarens variant kan antingen likna fonetiskt talarens L1, såsom finlandssvenska gör i finskspråkiga talares fall (Kuronen \& Leinonen 2010), eller ha ett tydligt annorlunda uttal, såsom sverigesvenska (se t.ex. Garlén 1988), kan begripligheten bero på lyssnarens variant. På grund av 
fonetiska likheter mellan finlandssvenska och finska samt finlandssvenska lyssnares vana vid finskspråkiga talares svenska förväntas uttalet vara lättare för finlandssvenska än för sverigesvenska lyssnare att begripa (se kap. 2). Hypotesen gällande den tredje forskningsfrågan baserar sig på liknande grund: jag antar att kunskaper i finska och mångsidiga språkfärdigheter gör det lättare att förstå brutet uttal. Jag antar vidare att begriplighetsvärderingarna följer talarens framgång i svenskstudierna (se kap. 2).

Kontexten av undersökningen inramas av finländsk gymnasieutbildning. Gymnasister är en relevant talargrupp eftersom ett muntligt delprov införs i studentexamen inom den närmaste framtiden. Grunden för gymnasieutbildning utgörs av en oftast nioårig läroplikt som det finländska skolsystemet baserar sig på (Opetushallitus 2017a,b). Svenska språket är ett av de obligatoriska läroämnena och det kan börja studeras tidigast i årskurs 2. Då kallas lärokursen för en lång lärokurs A1. Vanligast är dock att eleven läser en medellång lärokurs B1 i svenska (Ylioppilastutkintolautakunta 2016), vilket ända till hösten 2016 betydde att studierna i svenska började i årskurs 7. Fr.o.m. hösten 2016 trädde en ny läroplan i kraft och sedan dess har studierna i svenska börjat i årskurs 6 som 12-åring. Den medellånga lärokursen i gymnasiet omfattar fem obligatoriska kurser och två valfria kurser (GLGY 2003, 2015).

\section{Förståelighet och begriplighet: tal, talare och lyssnare}

Vid forskning som syftar till att analysera talarens förmåga att producera tal eller lyssnarens förmåga att förstå det har det oftast gjorts en skillnad mellan begreppen förståelighet (eng. intelligibility), begriplighet (eng. comprehensibility) och brytning (eng. accentedness) (t.ex. Saito m.fl. 2016; Field 2005; Munro \& Derwing 1995a). Begreppen är etablerade i uttalsforskning, speciellt med engelska som målspråk, men fastställda motsvarigheter i svenska saknas (se dock Sturesson 2016: 8). Orsaken till separata begrepp är olika analysmetoder. Företeelsen har nämligen undersökts inom lingvistik med olika metoder och uppgifter. Om lyssnarens uppgift är att identifiera vad talaren säger (t.ex. genom transkribering) används begreppet förståelighet (eng. intelligibility) (Munro \& Derwing 1995a). Fokusen ligger då på talaren och förmågan att producera tal. Testet är då objektivt (Fayer \& Krasinski 1987). Alternativt kan undersökningen fokusera på lyssnarens uppfattning om talets begriplighet. Lyssnaren värderar lättheten att förstå talet genom skalbedömning och i så fall talas det om begriplighet (eng. comprehensibility) (Munro \& Derwing 1995a). Begriplighetstest är lyssnarbaserat och subjektivt (Fayer \& Krasinski 1987). Med begreppet brytning (eng. accentedness) syftas på lyssnarens uppfattning om hur mycket uttalet avviker från målspråket, vilket analyseras ge- 
nom skalbedömning (Munro \& Derwing 1995a).

Fast tudelning i begriplighet och förståelighet är mycket vanlig inom förståelighetsundersökningar finns det dock studier som inte gör någon skillnad mellan begreppen och också studier som har annorlunda definitioner (t.ex. Smith 1992). Därför är det på plats att definiera hur begreppen används $i$ denna artikel. Begreppet förståelighet används om den objektiva förståeligheten (intelligibility), dvs. när metoden har varit identifiering eller transkription. Härutöver används detta begrepp då förståelighetsforskningen diskuteras på den allmänna nivån och då det inte har framgått i den hänvisade studien om den undersöker förståelighet eller begriplighet i den betydelse som beskrivits ovan. Begreppet begriplighet används då metoden har varit skalbedömning (comprehensibility) och begreppet brytning hänvisar till uttalsmässiga avvikelser från målspråket (accentedness). Metodologiskt sett undersöker den här studien begriplighet; lyssnarna har värderat begripligheten på en skala.

Förståeligheten har stått i fokus i flera studier och konstaterats relatera till flera delområden inom muntlig kommunikation, men starkast till uttalet (t.ex. Saito m.fl. 2016; Crowther m.fl. 2015; Field 2005; Kjellin 2002; Munro \& Derwing 1995a,b; Fayer \& Krasinski 1987; Albrechtsen m.fl. 1980). Att fastställa en generaliserbar hierarki över de mest kritiska uttalsfelen har varit utmanande eller till och med omöjligt för de undersökta språken och forskningsmetoderna har varit varierande (se Jesney 2004: 2; Pihko 1994). Därtill kan de påverkande faktorerna variera enligt talarens L1 (Crowther m.fl. 2015). Field (2005: 399) föreslår att prosodiska drag har universellt störst inverkan på förståeligheten. Ett förklarande exempel på detta gäller ordbetoningen: då man processar talet fäster man störst uppmärksamhet på den betonade stavelsen som förknippas med ett visst ord och med den viktigaste informationen i satsen. Således kan ett felaktigt betoningsmönster fördröja processen att uppfatta budskapet och vålla problem i förståeligheten (t.ex. Field 2005; Kjellin 2002; Munro \& Derwing 1995b; Bannert 1984). Prosodins betydelse för förståeligheten har också märkts av Lintunen (2014: 167) och Derwing \& Munro (1997): Felfriheten i prosodi (och också i grammatik) överväger segmental korrekthet. Också i svenska har prosodin en central roll. För nästan 40 år sedan listade Bannert (1980: 97) de prosodiska dragen som viktigaste inlärningsmål i svenskt uttal - och detsamma gäller fortfarande (Thorén 2008: 31; Bannert 2004: 64, 66). Drag som rytm, ord- och satsbetoning samt kvantitet är drag som har tänkts vara de mest kritiska för förståeligheten, övervägande segment (se Thorén 2008: 121; Kjellin 2002: 96). I stället för förståeligheten förknippas segmentfelen vanligen med brytning (Saito m. fl. 2016; Thorén 2008), som i sin tur också påverkar begripligheten. Ett starkt brutet uttal kan få lägre begriplighetsvärderingar (t.ex. Abelin \& Boyd 2000), men lyssnaren kan dock transkribera det talaren sagt helt korrekt (Munro \& Derwing 1995a). Med andra ord kan talaren förmedla budskapet, men det är svårt att uppfatta för lyssna- 
ren. Den låga begriplighetsvärderingen kan bero på processtiden hos lyssnaren vilken ökar om talet har stark brytning (Munro m.fl. 2006: 112). Å andra sidan finns det studier där korrelationen mellan begriplighet och brytning inte påträffats (t.ex. Munro \& Derwing 1995a). Brytningen kan också relatera till lyssnarens attityd, och den eventuella negativa attityden mot en talare med stark brytning eller begränsade språkkunskaper kan försämra begriplighetsvärderingen - lyssnaren vill inte ens förstå (Kjellin 2002: 15; Fayer \& Krasinski 1987).

Förutom uttal har andra lingvistiska och också icke-lingvistiska faktorer en inverkan på förståeligheten. Grammatik och lexikon, speciellt lexikal mångfald, relaterar till värderingen (Kennedy \& Trofimovich 2008; Albrechtsen m. fl. 1980), men relationen är dock inte så stark som till uttalet (Saito m. fl. 2016; Fayer \& Krasinski 1987). Därtill kan talhastighet (Munro \& Derwing 2001: t.ex.), tonhöjd (Abelin \& Boyd 2000), tvekan (Fayer \& Krasinski 1987), självkorrigering (Albrechtsen m.fl. 1980), lyssnarens tidigare kunskap om temat (se Kennedy \& Trofimovich 2008) och kännedom av genren och kulturen (Pihko 1994: 14) ha inverkan på förståeligheten. Vidare kan irritationen vara en orsak till - eller en följd av - svårförståeligheten: Lyssnaren kan bli irriterad till följd av konstanta fel och därför inte förstå, eller så kan lyssnaren bli irriterad då hen inte förstår (Fayer \& Krasinski 1987).

Vid sidan av talet i sig relaterar förståeligheten till vissa talar- och lyssnarmässiga bakgrundsfaktorer. Således är det väsentligt att bestämma vem som talar och vem som ska förstå talet då man undersöker förståeligheten. I största delen av tidigare förståelighetsundersökningar har målspråket varit engelska (för en översikt se Jesney 2004), som kan konstateras vara lingua franca - ett språk som man kommunicerar på med både L1- och L2-talare. Svenska studeras däremot för att man ska kunna kommunicera i Norden (GLGY 2003, 2015) och i första hand använda språket med och bli förstådd av L1-talare. Lyssnarperspektivet i förståeligheten, begripligheten och brytningen samt deras värdering innebär lyssnarens tidigare erfarenheter av talares L1 (Kennedy \& Trofimovich 2008; Wingstedt \& Schulman 1984) och av fonetik och uttal. L1lyssnare med tidigare kunskaper om talarens L1 kan ha lättare att förstå talare med stark brytning eller låga kunskaper i målspråket (Kennedy \& Trofimovich 2008; Wingstedt \& Schulman 1984) men å andra sidan är lyssnarvärderare som har samma L1 som talare mera kritiska i sina värderingar (Fayer \& Krasinski 1987). Strängare värderingar kan också ges av en oerfaren eller fonetiskt outbildad lyssnare (Jesney 2004: 8; Munro \& Derwing 1995b) om än inte alltid (t.ex. Saito m.fl. 2017; Kennedy \& Trofimovich 2008).

Uttalsfärdigheterna är således av central betydelse i muntlig kommunikation. Uttals- och språkinlärningen relaterar till ett flertal faktorer i talarbakgrunder, såsom exponeringsåldern och -tiden, det sociala umgänget, talares L1 osv. (se Ullakonoja \& Dufva 2016). Talarens erfarenheter av och kontakter 
med målspråket är betydelsefulla. Till exempel ett längre uppehåll i en målspråkig miljö stödjer uttalsinlärningen (t.ex. Ullakonoja 2011). Om uppehållet är svårt att arrangera eller om kontakterna med målspråket är svårtillgängliga har fritiden och skolan en stor betydelse för uttalsinlärningen (se Derwing \& Munro 2013). Speciellt målspråkiga fritidsaktiviteters betydelse för språkinlärningen har påvisats vara markant (t.ex. Huhta m.fl. 2016; Mustila 1990), men intresset för att använda svenska språket på fritiden är inte stort (Hildén \& Rautopuro 2014: 118-119). Framgången i svenskstudier verkar vara könsfördelad: flickor är mer motiverade och når bättre resultat i alla språkliga delområden än pojkar (t.ex. Hildén \& Rautopuro 2014: 77; Juurakko-Paavola \& Palviainen 2011; Tuokko 2002). Det är dock viktigt att minnas att de ovannämnda resultaten grundar sig på vitsordet, självbedömningen eller lärarbedömningen, inte på autentiska situationer eller L1-lyssnarbedömningar.

\section{Material, metoder och genomförande}

Materialet i den här undersökningen utgörs av upplästa talprov av finskspråkiga talare som har blivit begriplighetsvärderade av svenskspråkiga lyssnare. Talarna i undersökningen är 21 finskspråkiga gymnasister i åldrarna mellan 17 och 19 år. 16 av talarna är kvinnor och 5 är män, vilket kan sägas spegla könsfördelningen i kurserna i svenska. Alla talare har läst den medellånga lärokursen i svenska, dvs. börjat sina studier i svenska vid 13 års ålder. Talarna går i ett vanligt gymnasium i Finland. Vid insamlingstiden gick talarna på en valfri muntlig kurs (RUB6) som genomförs i slutskedet av studierna i svenska. Talarnas senaste vitsord i svenska varierade mellan 6 och 9 på en skala 4-10 så att fem talare hade vitsord 6, sju talare vitsord 7, sju talare vitsord 8 och en talare vitsord 9. En av talarna uppgav inte sitt vitsord. Ungefär hälften av talarna sade sig använda svenska på fritiden, dvs. de skriver, läser, talar och/eller lyssnar på svenska utanför skolan: Två talare använder svenska mer än en gång på två veckor och nio talare 1-2 gånger på två månader. Tio talare använder svenska inte alls på fritiden. Ingen av talarna sade sig ha tillbringat någon längre tid (mer än 2 månader) i något annat land än Finland.

I materialinsamlingen deltog sammanlagt 60 gymnasister. De som sade sig ha lässvårigheter e.d. bortvaldes och 21 finskspråkiga talare valdes med i undersökningen genom ett slumpmässigt urval. För att kunna försäkra lyssnarvärderingarnas reliabilitet användes fyra kontrolltalare som har svenska som hemspråk eller modersmål. Om en lyssnarvärderare inte hade gjort någon skillnad mellan målgruppen och kontrolltalarna tänktes värderingen inte ha gjorts med omsorg och värderingen uteslöts.

Som talmaterial i undersökningen användes en uppläst text (bilaga 1). Textens lexikala innehåll var avsett att vara okomplicerat och det innehåller inga 
tunga konstruktioner. Textens struktur och innehåll var tänkta att likna den nivå som en gymnasist sannolikt skulle använda i verklig kommunikation. Texten har utformats för undersökningsändamål och den innehåller alla svenska ljud och varierande stavelsetyper samt ord- och satsbetoningsmönster. Genom valet av textuppläsning som undersökningsmaterial uteslöts faktorer som inte har med uttalet att göra, såsom grammatik eller lexikon. Jämfört med textuppläsning är spontant tal dock vanligare i förståelighets- och begriplighetsundersökningar (t.ex. Saito m.fl. 2016; Derwing \& Munro 1997; Munro \& Derwing 1995a; Fayer \& Krasinski 1987), men att samla in material med spontant tal som skulle vara uttalsmässigt lika omfattande som en uppläst text kunde leda till långa talprov och ändå kan man inte garantera att alla aspekter kommer med $\mathrm{i}$ undersökningen. Man har inte heller kunnat se att textuppläsning skulle ge annorlunda resultat än spontant tal (Jesney 2004: 5). Det är dock viktigt att minnas att också textuppläsning kan innebära faktorer som påverkar värderingen men inte har någonting med uttalet att göra, t.ex. omtagningar (se Albrechtsen m.fl. 1980) och tvekande (Fayer \& Krasinski 1987).

Inspelningarna utfördes med fyra olika gymnasistgrupper varav tre (41 gymnasister) inspelades i ett språklaboratorium med utrustningen Sanako Lab 100 och en grupp (19 gymnasister) med Roland -inspelningsapparater. Kontrolltalarna var med i de inspelade grupperna förutom en kontrolltalare som inspelades separat i en tyst lokal med en digital Zoom H2 -inspelningsapparat. Talarna fick ca 3 minuter på sig att bekanta sig med texten och ställa eventuella frågor om den före inläsningen. Om det blev felsägningar eller om talaren kände sig missnöjd med uttalet, fick hen läsa om hela meningen, och den bästa varianten valdes med i undersökningen. Att inläsa texten tog från 80 till 130 sekunder. Talproven i lyssnartestet gjordes genom att indela den upplästa texten i sju delar så att längden på talproven blev från 22 till 31 ord (ca 10-20 sekunder). Varje talares talprov valdes slumpmässigt.

Lyssnarna i undersökningen är sammanlagt 64 finlandssvenska och sverigesvenska deltagare. Den finlandssvenska lyssnargruppen (senare i texten FISV-lyssnare) utgörs av 35 lyssnare (30 kvinnor, 5 män). FISV-lyssnarnas ålder fördelar sig relativt jämnt men största delen var 36-65-åriga $(n=24)$. Över hälften av FISV-lyssnarna har utbildat sig vid universitet $(n=21)$. Av FISVlyssnarna använde 31 endast svenska hemma som barn och 4 lyssnare använde sig svenska och finska som barn. Förutom svenska har största delen kunskaper i engelska $(n=33)$, tyska $(n=29)$ och finska $(n=25)$. Den språkliga mångfalden, dvs. hur många språk lyssnarna behärskar förutom modersmålet, är relativt varierande men för det mesta har FISV-lyssnarna kunskaper i två språk förutom svenska. Dialekt talar 14 lyssnare medan 21 sade sig inte tala någon dialekt. Lyssnarnas kontakter med finskan utreddes med en skala från o (= inga) till 5 (= mycket) och nästan hälften (48,6 \%) av FISV-lyssnarna har mycket kontakter (5) med finska. 
Den sverigesvenska lyssnargruppen (senare i texten SVSV-lyssnarna) består av 29 personer (18 kvinnor, 9 män, 2 ville inte uppge sitt kön). Jämfört med FISV-lyssnargruppen är SVSV-lyssnarna lite yngre. Största delen är 2535-åringar ( $n=13)$, annars är åldersfördelningen jämn. Såsom FISV-lyssnarna uppgav nästan alla $(n=26)$ SVSV-lyssnare ha använt endast svenska hemma som barn, men tre lyssnare hade också haft något annat hemspråk. Alla SVSVlyssnare har universitetsutbildning. Alla SVSV-lyssnare har kunskaper i engelska $(n=29)$ och största delen också i tyska $(n=19)$ och franska $(n=15)$. Den språkliga mångfalden liknar FISV-lyssnarna: största delen av SVSV-lyssnarna har kunskaper i två språk förutom svenska. SVSV-lyssnarnas kontakter med finska språket är mindre än FISV-lyssnarnas: $79 \%$ av SVSV-lyssnarna har inga eller nästan inga kontakter med finskan (o-2 på en skala från o (= inga) till 5 (= mycket)). 14 lyssnare sade sig tala någon svensk dialekt, 15 lyssnare uppgav att de inte talar någon dialekt.

Lyssnarna önskades representera potentiella åhörare för gymnasisterna, dvs. vanliga svenskspråkiga personer. De rekryterades med ett sätt som liknar snöbollsurval: begriplighetsvärderingen utfördes på nätet och länken till lyssnartestet skickades till personer som tänktes ha möjligheten att sprida ut länken till eventuella lyssnare. I lyssnartestet deltog sammanlagt 101 lyssnare, varav 61 använder finlandssvensk och 40 sverigesvensk variant. Från lyssnargruppen bortvaldes de som angav sig ha använt något annat språk än svenska hemma som barn eller ha något annat primärt vardagsspråk än svenska. Bara lyssnare som sade sig ha normal hörsel togs med i undersökningen. Några av lyssnarna visade sig inte göra någon skillnad mellan målgruppen och kontrolltalarna och deras svar ansågs opålitliga och bortvaldes. Ett lyssnartest genomfördes separat med en större grupp $(n=12)$ i en sal med högtalare, men denna grupp uteslöts ur undersökningen på grund av avvikande omständigheter. Efter urvalsprocessen blev det slutliga lyssnarantalet i undersökningen det ovannämnda 64 (35 FISV och 29 SVSV).

Talproven laddades in i ett nätbaserat program SoGo Survey där de presenterades i ett fyrsidigt formulär. Varje sida hade 6 eller 7 talprov med olika textinnehåll, inklusive kontrolltalarnas talprov. Således upprepades talprov med samma textinnehåll 3-4 gånger under lyssnartestet, vilket kunde göra värderingen något onaturlig och därför blev lyssnarna informerade om upprepandet inför testet. Talproven presenterades i en slumpmässig ordning på var sin sida. I anslutning till lyssnartestet svarade lyssnarna på bakgrundsfrågor och lyssnartestet tog sammantaget ca 20 minuter. Alla lyssnare ombads att använda hörlurar och göra testet i en tyst lokal. Alla lyssnare värderade begripligheten av alla 25 talprov (varav 4 var kontrolltalare) i testet så att undersökningen omfattar sammanlagt 1600 enskilda värderingar (1344 målgruppstalare + 256 kontrolltalare).

Begriplighetsvärderingen genomfördes med en verbaliserad skala på 1-7. 
Detta passar bra i undersökningar med fonetiskt outbildade lyssnare och är lättare att använda för lyssnare och forskare än en niogradig skala, som dock oftast används i uttalsundersökningar (Isaacs \& Thomson 2013; Jesney 2004: 2). För att underlätta både värderingen och analysen var skalan verbaliserad:

1 - förstod ingenting

2 - förstod ett par ord

3 - förstod några saker men helheten blev oklar

4 - förstod helheten men några saker blev oklara

5 - förstod allt men behövde koncentrera mig noga

6 - förstod allt

7 - förstod allt med lätthet

- - vet ej

Forskningsfrågorna besvarades genom statistisk undersökning av lyssnarsvaren. Medelvärdet $(\mathrm{M})$, medianen ( $\mathrm{md}$ ) och typtalet (Mo) räknades med alla värderingar sammanlagt. På så sätt utreddes de talarmässiga värderingarna och fördelningen av dem. Den andra och den tredje forskningsfrågan analyserades genom att jämföra värderingarna som lyssnare med olika bakgrundsfaktorer gett och talare med olika bakgrundsfaktorer fått. Vid sidan av att gruppera talarna enligt de bakgrundsfaktorer (kön, vitsord, kunskaper i enskilda språk, fritidsaktiviteter osv.) som testades och att jämföra medelvärden mellan grupperna, analyserades det också om relationen mellan värderingarna och den ifrågavarande bakgrundsfaktorn är statistiskt signifikant. Relationsanalyserna genomfördes med t-test och korrelationstest (Pearson correlation). Ytterligare analyserades relationen mellan talarmässiga bakgrundsfaktorer och begriplighetvärderingar statistiskt med Friedman test.

Resultaten är statistiskt signifikanta om värdet är mindre än $p=0,05$ och korrelationen mycket stark om värdet är nära $r=1,0$. Förkortningen $t$ syftar till $\mathrm{t}$-testvariabeln och förkortningen $\mathrm{F}$ till storleken på testvärdet. Frihetsgraden har markerats med förkortningen $\mathrm{df}$.

\section{Resultat}

I det här kapitlet presenteras resultaten gällande begriplighetsvärderingar samt deras relation till lyssnarnas och talarnas bakgrunder. Hur begripligt gymnasisters uttal har ansetts vara av alla lyssnare sammanlagt presenteras i avsnitt 4.1. Begriplighetsvärderingarna behandlas enligt lyssnarnas variant i avsnitt 4.2. I avsnitt 4.3 tas upp begriplighetsvärderingarnas relation till andra 


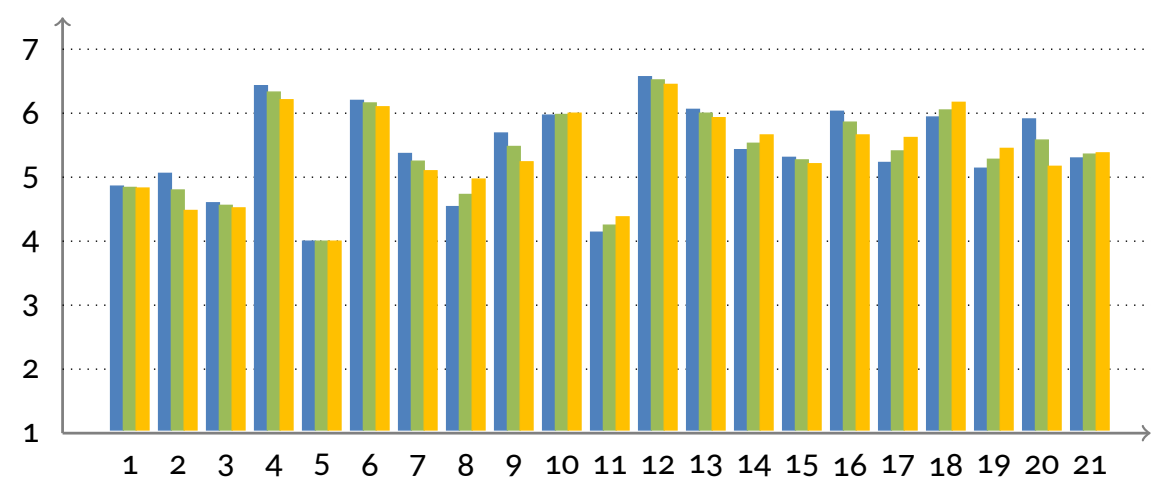

FIGUR 1. Talarmässiga medelvärden av FISV- och SVSV-lyssnarnas samt alla lyssnarnas begriplighetsvärderingar på skala 1-7. Värderingarna givna av FISV-lyssnarna har markerats till vänster med blå färg, av SVSV-lyssnarna till höger med gul färg och alla lyssnares genomsnitt har markerats i mitten med grön färg.

bakgrundsfaktorer gällande såväl lyssnarna som talarna och i avsnitt 4.4 behandlas upprepandet av samma textinnehåll och bakgrundsbruset.

\subsection{Begripligheten}

Syftet med den första forskningsfrågan var att analysera hur begripligt finskspråkiga gymnasister uttalar svenska. Resultaten (båda lyssnargrupperna sammanlagt) visar att uttalet är förståeligt men lyssnaren behöver koncentrera sig noga. Medelvärdet för värderingarna är $5,39(\mathrm{md}=5, \mathrm{Mo}=5)$ på skalan 1-7.

Medelvärden som talarna fick varierar mellan 4,00-6,52 ( $\mathrm{md}=4-7$, $\mathrm{Mo}=4-7)$. Värderingen som största delen av talarna $(n=10)$ fick var 5 - förstod allt men behövde koncentrera mig noga ( $\mathrm{M} 5,28-5,98)$. Sex talare värderades med 4 - förstod helheten, men några saker blev oklara ( $M$ 4,00-4,84) och fem talare nådde värderingen 6 - förstod allt (M 6,00-6,52) (Figur 1). Resultaten skiljer sig delvis från Hildéns (2000: 246) antagande om att uttalet knappast vållar förståelighetsproblem: begripligt uttal var ingen självklarhet $\mathrm{i}$ alla talprov, men största delen blev dock någorlunda förstådda.

\subsection{Variantens påverkan}

Syftet med den andra forskningsfrågan var att analysera om det finns någon skillnad mellan begriplighetsvärderingarna givna av finlandssvenska respektive sverigesvenska lyssnare. FISV-lyssnarna värderade talprovens begriplighet med medelvärdet 5,42 $(\mathrm{md}=5, \mathrm{Mo}=5)$. De talarmässiga medelvärdena varierar mellan 4,00-6,57 ( $\mathrm{md}=4-7, \mathrm{Mo}=4-7)$. Talare som fick värderingen 5 förstod allt men behövde koncentrera mig noga $(M=5,06-5,97)$ utgjorde den största gruppen $(n=11)$. Värderingen 4 - förstod helheten, men några saker 
blev oklara $(4,00-4,86)$ fick 5 talare. Värderingen 6 - förstod allt $(6,03-6,57)$ eller högre fick 5 talare (se Figur 1 ).

Medelvärdet för begriplighetsvärderingarna som SVSV-lyssnarna gav var bara en aning lägre en FISV-lyssnarnas: $5,36(\mathrm{md}=5, \mathrm{Mo}=5)$. Medelvärdena varierade mellan 4,00-6,45 ( $\mathrm{md}=4-7$, Mo 4-7). I likhet med FISV-lyssnarna gav SVSV-lyssnarna värderingen 5 - förstod allt men behövde koncentrera mig noga ( $M 5,10-5,93)$ àt största delen av talarna $(n=10)$. Talare med värderingen 4 - förstod helheten, men några saker blev oklara ( $M$ 4,00-4,97) blev 6, en fler jämfört med FISV-talarna. Värderingen 6 - förstod allt (M 6,00-6,45) eller högre fick 5 talare. (Figur 1.)

Undersökningsresultaten visar alltså att finskspråkiga gymnasisters uttal av svenska är genomsnittligt lika begripligt för en FISV- och SVSV-lyssnare. Mellan medelvärdena finns det praktiskt taget ingen skillnad: 5,42 (FISV-lyssnarna) respektive 5,36 (SVSV-lyssnarna) utgör en skillnad på 0,06. Begriplighetsvärderingens relation till varianten är inte statistiskt signifikant $(t=-0,467, d f=62$, $p=0,642$ ), och mellan värderingarna givna av finlandssvenska lyssnare och sverigesvenska lyssnare finns en stark korrelation: talarmässigt är korrelationen $r=0,901$ och genomsnittligt $r=0,948$, vilket visar att värderingarna är mycket eniga.

Båda lyssnargrupperna gav den högsta värderingen åt samma talare (talare 12) (M FISV 6,57/ SVSV 6,45) och den lägsta värderingen åt samma talare (talare 5) (M FISV 4,00/ SVSV 4,00). Annars varierade ordningen mellan talarnas begriplighetsvärderingar i viss mån. Vissa talare värderades vara begripligare för lyssnare av ena varianten än den andra. Två talare (talare 2 och 20) värderades statistiskt signifikant lättare att förstå av FISV-lyssnarna än av SVSV-lyssnarna ( $t=-2,956, d f=62, p=0,004$ och $t=-2,934, d f=62, p=0,005$ ).

\subsection{Andra bakgrundsfaktorers påverkan}

Målet med den tredje forskningsfrågan var att utreda om det finns övriga lyssnar- eller talarmässiga bakgrundsfaktorer (se även kap. 2) som relaterar till värderingarna. Eftersom värderingarna av FISV-lyssnarna och SVSV-lyssnarna visade sig vara likriktade kunde lyssnargruppernas begriplighetsvärderingar förenas och analysen av bakgrundsfaktorernas påverkan göras med sammanslagna lyssnargrupper. Vid analysen av talarmässiga bakgrundsfaktorer (avsnitt 4.3.2) är det viktigt att minnas att samplet var litet, i synnerhet då talargruppen har indelats i mindre grupper enligt kön, vitsord och fritidsaktiviteter. Resultaten är således inte generaliserbara men de kan dock tänkas vara riktgivande. 


\subsubsection{Lyssnarmässiga bakgrundsfaktorer}

I analysen hittades anmärkningsvärt få lyssnarmässiga bakgrundsfaktorer som relaterade till begriplighetsvärderingen. Värderingarna relaterade inte till lyssnares ålder $(r=0,201, p=0,110)$ eller kön $(t=0,586, d f=60, p=0,560)$, bara utbildningens relation till värderingen var statistiskt signifikant $(r=-0,251$, $p=0,046)$. Enligt resultaten gav lyssnare med universitetsutbildning strängare värderingar, men det är väsentligt att beakta att representanter av andra utbildningar var få.

Ett oväntat resultat var att lyssnarens kunskaper i finska inte hade något samband med värderingen ( $t=-0,377, d f=62, p=0,707)$. FISV-lyssnarna med kunskaper i finska verkade värdera begripligheten till och med lite lägre än andra FISV-lyssnare (M kan finska 5,34/kan inte finska 5,61), medan med SVSVlyssnarna var det tvärtom ( $M$ kan finska 5,48/kan inte finska 5,38). Lyssnarnas kontakter med finska $(r=0,036, p=0,779)$ och SVSV-lyssnarnas kontakter med finlandssvenska $(r=-0,003, p=0,986)$ hade inte heller något samband med begriplighetsvärderingen. Härutöver relaterade mångsidiga språkkunskaper inte till begripligheten $(r=0,150, p=0,236)$, inte heller kunskaper i enstaka språk $(t=1,300, d=62, p=0,198-t=-0,279, d f=62, p=0,781)$. Kunskaper $i$ tyska tycks visserligen ha hjälpt svsv-lyssnarna att förstå talarnas svenska ( $M$ kan tyska 5,44/kan inte tyska 5,20), men resultatet var inte statistiskt signifikant. Om lyssnaren talar dialekt eller inte relaterade inte heller till begriplighetsvärderingen $(t=0,348, d f=62, p=0,729)$.

\subsubsection{Talarmässiga bakgrundsfaktorer}

Såsom lyssnares kön relaterade inte heller talares kön till begriplighetsvärderingen $(t=-0,467, d f=62, p=0,642)$. Medelvärdet 5,39 som kvinnliga talare fick är ytterst nära värdet 5,40 som manliga talare fick. Resultatet avviker från tidigare iakttagelser om könsfördelningen gällande framgången i svenskstudier (se kap. 2).

En intressant korrelation hittades mellan talarens senaste vitsord i svenska och begriplighetsvärderingen: korrelationen är negativ, dvs. talarna med ett lägre vitsord fick en högre begriplighetsvärdering och vice versa (Figur 2). Den enda talare som hade vitsord 9 fick dock den högsta begriplighetsvärderingen. Resultaten är statistiskt signifikanta $(F=23,543, d f=2, p=0,000)$ förutom värderingarna mellan vitsord 7 och $8(p=0,279)$. Detta stämmer med Hildéns (2000) iakttagelser - studerande med vitsord 8 gör mera fel i svenskt uttal och talar mindre flytande. Talare med berömliga vitsord (9-10) hade dock bäst uttal både i Hildéns och i denna undersökning. Med vitsordet i andra språk verkade dock finnas en motsatt tendens. Talarna vars medelvärde av vitsord som de senast fått i andra språk är $6(n=4)$ fick medelvärdet 4,97, vitsord $7(n=5)$ 5,30 , vitsord $8(n=7) 5,45$ och vitsord $9(n=5)$ medelvärdet 5,69. Resultaten 
5,6

5,4

5,2

5,0

4,8

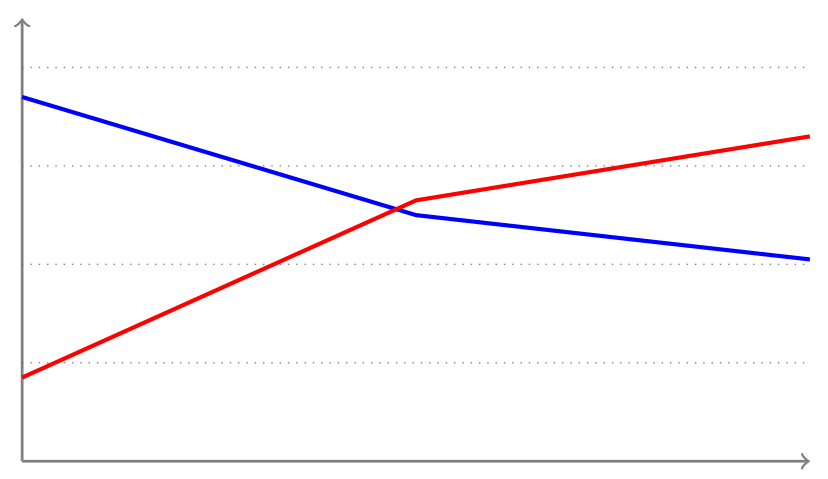

vitsord 6

vitsord 7

vitsord 8

FIGUR 2. Begriplighetsvärderingarnas relation till det vitsord som talaren senast fått. Med blå färg vitsord i svenska, med röd färg vitsord i andra språk.

är statistiskt signifikanta $(F=51,687, d f=3, p=0,000)$ förutom mellan vitsord 7-8 $(p=0,485)$ och 8-9 $(p=0,131)$ (Figur 2). Detta kan tyda på att vitsordet $i$ svenska inte mäter färdigheter i uttal.

Svenskspråkiga fritidsaktiviteter verkade förbättra begripligheten: korrelationen med begriplighetvärderingen var positiv (jfr kap 2). Om talare använder svenska på fritiden hade hen värderats vara begripligare $(M 5,71)$ än den som inte gör det (M 5,04). Till och med få fritidsaktiviteter med svenska såg ut att förbättra begripligheten. De talare som använde svenska mer än en gång per vecka fick medelvärdet 6,25, 1-2 gånger på 2 månader medelvärdet 5,59 och de som inte alls sysslade med svenska språket medelvärdet fick 5,04 (Figur 3). Resultatet är statistiskt signifikant $(F=114,361, d f=2, p=0,000)$.

\section{4 Övriga kommentarer}

Som väntat fick kontrolltalarna de högsta begriplighetsvärderingarna (M 6,667,00). Ändå fanns det några skillnader mellan dessa värderingar. Kontrolltalare som hade fått den högsta värderingen av FISV-lyssnarna använde den finlandssvenska varianten (M FISV 7/SVSV 6,86), medan SVSV-lyssnarna gav kontrolltalaren med den sverigesvenska varianten den högsta värderingen (M SVSV 6,90/ FISV 6,89).

Oavsett påpekandet i anvisningarna misstänkte några lyssnare i slutkommentarerna att upprepandet av samma textinnehåll hade påverkat begriplighetsvärderingen. Påverkan kunde dock inte konstateras vara kraftig. I Figur 1 visas talproven med värderingarna i den ordning som de blev uppspelade (dock slumpmässigt på sidorna). Värderingarna av de sista talproven avviker inte stort från de första talproven. Därtill listades begriplighetsvärderingarna av talproven med samma textinnehåll i spelordningen och det kunde märkas 


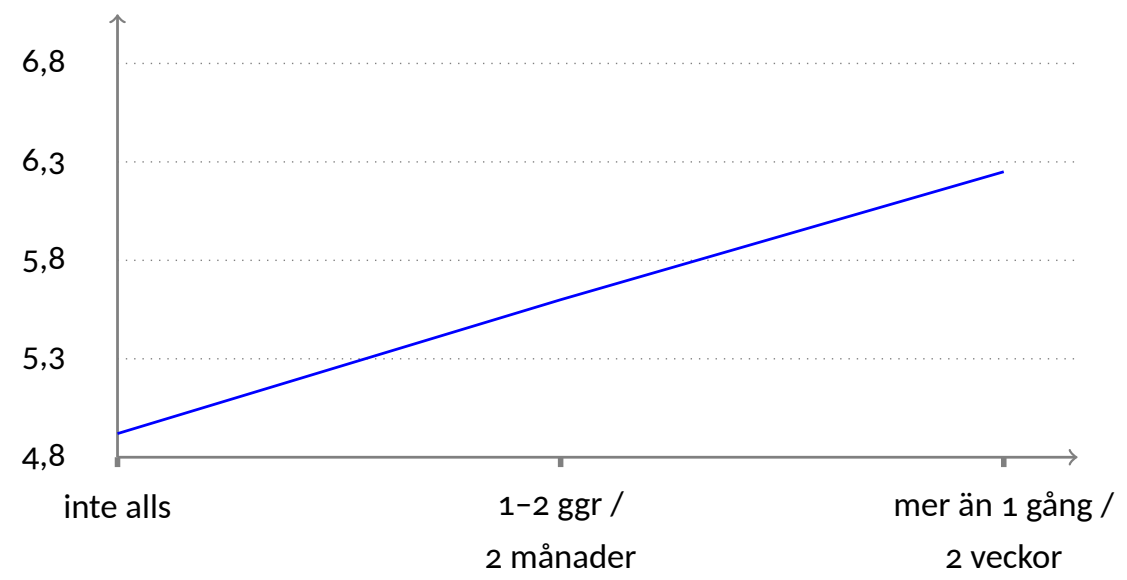

FIGUR 3. Begriplighetsvärderingarnas relation till talarnas fritidsaktiviteter på svenska.

att värderingarna av de senare spelade talproven inte var konsekvent högre. Några lyssnare kommenterade att bakgrundsbruset också kan ha påverkat begripligheten. Påverkan kunde inte heller konstateras ha varit stor. Talproven med något bakgrundsbrus $(1,6,8,9,10,11,13,14,15,17,21)$ värderades inte lägre än andra (se Figur 1).

\section{Sammanfattande diskussion}

Den här undersökningen har visat att finskspråkiga talares svenska uttal är begripligt men lyssnaren behöver koncentrera sig noga. Begriplighetsvärderingarna är inte beroende av lyssnarens variant, kön, ålder eller bakgrundsfaktorer som berör språket. De enda två bakgrundsfaktorer som relaterar till talprovens begriplighetsvärdering gäller talarna. Vitsord som talaren senast fått i svenska korrelerar negativt med begriplighetsvärderingen medan talarens fritidsaktiviteter på svenska har en positiv korrelation med begripligheten.

I motsats till vad som förväntades är lyssnarvärderingarna givna av den finlandssvenska och den sverigesvenska lyssnargruppen samstämmiga. Eftersom finska och finlandssvenska liknar varandra fonetiskt såväl på segmentell som på prosodisk nivå (Kuronen \& Leinonen 2010) antogs FISV-lyssnarna ge högre värderingar än SVSV-lyssnarna. FISV-lyssnarnas värderingar är bara en aning högre än SVSV-lyssnarnas. Inte heller relaterar lyssnarnas erfarenheter av talarnas L1, dvs. finska, till begripligheten. FISV-lyssnare med kunskaper i finska verkar till och med ge lägre värderingar än lyssnare med inga kunskaper $\mathrm{i}$ finska. Detta kan antas anknyta till toleransen (jfr Munro m.fl. 2006; Fayer \& Krasinski 1987), vilket uppmärksammas i värderingar av fyra uteslutna FISV- 
lyssnare som uppgav att de i stället för svenska använde främst finska i vardagen: de värderade begripligheten strängare $(M 5,14)$ än de som använde mest svenska i vardagen (M 5,42). Om talaren däremot har stark brytning eller låga kunskaper i L2-språk förstås hen bättre av lyssnare med erfarenheter av talarens L1 (Kennedy \& Trofimovich 2008; Wingstedt \& Schulman 1984), vilket syns svagt i värderingarna av SVSV-lyssnarna: lyssnare med kunskaper i finska värderade begripligheten en aning högre än de som saknade kunskaper i finska.

De faktorer som ser ut att relatera till begriplighetsvärderingen gäller talarnas språkliga bakgrund, närmare sagt vitsord och intresse för svenska språket. Ett bra vitsord i svenska verkar inte garantera ett begripligt uttal - snarare tvärtom. Begripligheten värderades allra lägst hos de talare vars senaste vitsord i svenska var 8, medan hos talare med vitsord 6 värderades begripligheten vara allra högst (bortsett från den enda talaren med vitsord 9). Hildén (2000) antar att företeelsen sammanhänger med artikulatorisk medvetenhet: medvetenheten om fonologin kan försämra det fonologiska flytet (de Bot 1992; Krashen 1982 i Hildén 2000: 279-280). Den fonologiska medvetenheten kan verkligen skapa viss osäkerhet hos avancerade inlärare, men inlärare som fått uttalsundervisning betraktar sitt uttal vara bra och de är också villiga att lära sig mera om uttalet (Lintunen \& Mäkilähde 2018). Antagandet att gymnasisterna lider av fonologisk medvetenhet strider delvis mot tidigare undersökningar enligt vilka muntlig kommunikation (Takala 1993) och speciellt uttal (Lintunen \& Mäkilähde 2018; Tergujeff 2013; livonen \& Tella 2009) förbises i den finska språkundervisningen, och således skulle inte heller talarna i den här studien vara fonologiskt medvetna. En tänkbar faktor är att språkinlärningen är subtraktiv. Då språkundervisningen i gymnasiet koncentrerar sig mest på skriftliga kunskaper får de gymnasister som absorberar dem ett bättre vitsord. Med andra ord fungerar vitsordet som mätare för skriftliga kunskaper. Om språkundervisningen betonar kraftfullt skriftliga kunskaper och muntliga kunskaper inte övas eller används blir det obalans mellan de språkliga delområdena. Detta kan leda till att de skriftliga kunskaperna börjar dominera kognitivt vilket kan resultera i försämrat uttal. Baserat på de ovannämnda undersökningarna kan det antas att orsaken till det högre vitsordets negativa korrelation med begriplighetsvärderingen snarare ligger i obalansen mellan de språkliga delområdena i språkundervisningen än i den fonologiska medvetenheten. En undersökning som ger mer detaljerad kunskap om företeelsen behövs.

I stället för vitsordet visar sig begripligheten korrelera positivt med användning av svenska utanför studierna. De talare som uppgav att de använder svenska på fritiden fick bättre resultat än de som inte alls använde svenska utanför studierna. Till och med ett litet antal aktiviteter på svenska på fritiden tycks ha en inverkan. Motsvarande resultat har fåtts också tidigare: studerande som intresserar sig för målspråket utanför skolan har bättre kunskaper (Huhta 
m. fl. 2016; Hildén \& Rautopuro 2014; Mustila 1990). Eftersom studenter sällan styrs självständigt in i informella inlärningssituationer (Hildén \& Rautopuro 2014) är det viktigt att svensklärarna uppmuntrar sina studenter att använda svenska också på fritiden.

Ett resultat som avviker från den stereotypa uppfattningen gäller talarens kön. Fastän pojkarnas framgång i svenskstudier har bedömts vara lägre än flickornas (se t.ex. Hildén \& Rautopuro 2014: 77; Juurakko-Paavola \& Palviainen 2011; Sajavaara 2006; Tuokko 2002) och pojkar ansetts vara omotiverade och mindre framgångsrika inlärare av svenska (se t.ex. Sajavaara 2006), visar resultaten av denna undersökning att manliga talare uttalar svenska lika begripligt som kvinnliga talare, till och med en aning begripligare.

\section{Tackord}

Den här undersökningen har gett mångsidig kunskap om finskspråkiga talares uttal av svenska, och den erbjuder flera forskningsfrågor till fortsatta undersökningar. För att kunna genomföra undersökningen fick jag ett arbetsstipendium av Svenska kulturfonden vilket jag är tacksam för. Värdefullt stöd har jag fått av projektet FOKUS vid Jyväskylä universitet, vilket jag också vill rikta ett stort tack till.

\section{Referenser}

Abelin, Å. \& S. Boyd 2000. Voice quality, foreign accent and attitudes to speakers. I A. Botinis \& N. Torstensson (red.) Proceedings of Fonetik 2000. Skövde: Högskolan i Skövde, 21-24.

Abercrombie, D. 1949. Teaching pronunciation. ELT Journal, 3 (5), 113-122.

Albrechtsen, D., B. Henriksen \& C. Faerch 1980. Native speaker reactions to learners' spoken interlanguage. Language Learning, 30 (2), 365-396.

Bannert, R. 1980. Svårigheter med svenskt uttal: inventering och prioritering. Praktisk lingvistik 5. Lund: Institutionen för lingvistik, Lunds universitet.

- 1984. Problems in learning Swedish pronunciation and in understanding foreign accent. Folia Linguistica, 18 (1-2), 193-222.

- 2004. På väg mot svenskt uttal. Lund: Studentlitteratur.

Crowther, D., P. Trofimovich, K. Saito \& T. Isaacs 2015. Second language comprehensibility revisited: investigating the effects of learner background. TESOL Quarterly, 49 (4), 814-837. DOI: 10.1002/tesq.203.

de Bot, K. 1992. A bilingual production model: Levelt's "speaking" model adapted. Applied Linguistics, 13 (1), 1-24. 
Derwing, T. M. \& M. J. Munro 1997. Accent, intelligibility and comprehensibility: evidence from four L1s. Studies in Second Language Acquisition, 20 (1), 1-16. https : / / www . cambridge . org / core / journals / studies - in - second - language acquisition/article/div-classtitleaccent-intelligibility-and-comprehensibilitydiv/ 729C15F62F9EC9A51A33EAB5C2Do5EDo.

- 2013. The development of $L 2$ oral language skills in two L1 groups: a 7-year study. Language Learning, 63 (2), 163-185. DOI: 10.1111/lang.12000.

Fayer, J. \& E. Krasinski 1987. Native and nonnative judgments of intelligibility and irritation. Language Learning, 37 (3), 313-326.

Field, J. 2005. Intelligibility and the listener: the role of lexical stress. TESOL Quarterly, 39 (3), 399-423. DOI: 10.2307/3588487.

Garlén, C. 1988. Svenskans fonologi. Lund: Studentlitteratur.

GLGY 2003. Grunderna för gymnasiets läroplan 2003. Helsingfors: Utbildningsstyrelsen. http : / / www . oph . fi / lagar_och _ anvisningar / laroplans - _och _ examensgrunder/gymnasiet [hämtad 2016-11-29].

- 2015. Grunderna för gymnasiets läroplan 2015. Helsingfors: Utbildningsstyrelsen. http://www.oph.fi/lagar_och_anvisningar/laroplans-_och_examensgrunder/ gymnasiet [hämtad 2016-11-29].

Hildén, R. 2000. Att tala bra, bättre och bäst: suomenkielisten abiturienttien ruotsin kielen suullinen taito testisuoritusten valossa. Helsinki: Helsingin yliopisto.

Hildén, R. \& J. Rautopuro 2014. Ruotsin kielen A-oppimäärän oppimistulokset perusopetuksen päättövaiheessa 2013. Helsinki: Opetushallitus.

Huhta, A., J. Alderson, L. Nieminen \& R. Ullakonoja 2016. The role of background factors in the diagnosis of SFL reading ability. I D. Tsagari \& J. Banerjee (red.) Contemporary Second Language Assessment. Contemporary applied linguistics 4. London: Bloomsbury, 125-146.

livonen, A. \& S. Tella 2009. Vieraan kielen ääntämisen ja kuulemisen opetus ja harjoittelu. I O. Aaltonen, R. Aulanko, A. livonen, A. Klippi \& M. Vainio (red.) Puhuva ihminen: puhetieteiden perusteet. Helsinki: Otava, 269-281.

Isaacs, T. \& R. Thomson 2013. Rater experience, rating scale length, and judgments of L2 pronunciation. Language Assessment Quarterly, 10 (2), 135-159. DOI: 10. 1080/15434303.2013.769545.

Jesney, K. 2004. The use of global foreign accent rating in studies of L2 acquisition. Calgary: Language Research Centre, University of Calgary. http://arts.ucalgary. $\mathrm{ca} / \mathrm{Irc} / \mathrm{research} / \mathrm{reports}$ [hämtad 2017-5-30].

Juurakko-Paavola, T. \& Å. Palviainen 2011. Svenskan i den finska skolan och högre utbildningen: om kunskaper och motivation genom olika utbildningsstadier. HAMKin julkaisuja 11/2011. Hämeenlinna: Hämeen ammattikorkeakoulu. http://urn. fi/URN:NBN:fi:jyu-201502241365.

Kennedy, S. \& P. Trofimovich 2008. Intelligibility, comprehensibility, and accentedness of $L 2$ speech: the role of listener experience and semantic context. The Canadian Modern Language Review, 64 (3), 459-489. DOI: 10.3138/cmlr.64.3.459.

Kjellin, O. 2002. Uttalet, språket och hjärnan: teori och metodik för språkundervisningen. Uppsala: Hallgren \& Fallgren.

Krashen, S. 1982. Principles and practice in second language acquisition. Oxford: Pergamon Press. http://www.sdkrashen.com/content/books/principles_and_ practice.pdf. 
Kuronen, M. \& K. Leinonen 2010. Svenskt uttal för finskspråkiga: teori och övningar i finlandssvenskt och rikssvenskt uttal. Tampere: Juvenes Print.

Lintunen, P. 2014. Ääntämisen oppiminen ja opettaminen. I P. Pietilä \& P. Lintunen (red.) Kuinka kieltä opitaan: opas vieraan kielen opettajalle ja opiskelijalle. Helsinki: Gaudeamus, 165-187.

Lintunen, P. \& A. Mäkilähde 2018. Short- and long-term effects of pronunciation teaching: EFL learners' views. I J. Volin \& R. Skarnitzl (red.) Pronunciation of English by speakers of other languages. Newcastle upon Tyne: Cambridge Scholars Publishing, 46-72.

Munro, M. J. \& T. M. Derwing 1995a. Foreign accent, comprehensibility, and intelligibility in the speech of secong language learners. Language Learning, 45 (1), 7397.

- 1995b. Processing time, accent, and comprehensibility in the perception of native and foreign-accented speech. Language and Speech, 38 (3), 289-306.

- 2001. Modeling perceptions of the accentedness and comprehensibility of L2 speech: the role of speaking rate. Studies in Second Language Acquisition, 23 (4), 451-468.

Munro, M. J., T. M. Derwing \& S. Morton 2006. Mutual intelligibility of L2-speech: language learning. Studies in Second Language Acquisition, 28 (1), 111-131. DOI: 10.1017/So272263106060049.

Mustila, E. 1990. Finska gymnasieelevers motivation för, attityder till och intresse för svenska. Tutkimuksia 125. Helsinki: Helsingin yliopiston kasvatustieteen laitos.

Opetushallitus 1994. Lukion opetussuunnitelman perusteet. Helsinki: Opetushallitus.

- 2017a. Gymnasiet. http://www.oph.fi/utbildning_och_examina/gymnasiet [hämtad 2017-1-9].

— 2017b. Läroplikt och skola. http://www.oph.fi/utbildning_och_examen / grundlaggande_utbildning/laroplikt_och_skola [hämtad 2017-1-9].

Pihko, M. 1994. Cross-linguistic intelligibility of native and non-native L2 speech varieties. Jyväskylä: Korkeakoulujen kielikeskus, Jyväskylän yliopisto.

Saito, K., P. Trofimovich \& T. Isaacs 2016. Second language speech production: investigating linguistic correlates of comprehensibility and accentedness for learners at different ability levels. Applied Psycholinguistics, 37 (2), 217-240. DOI: 10.1017/ So142716414000502.

- 2017. Using listener judgments to investigate linguistic influences on L2 comprehensibility and accentedness: a validation and generalization study. Applied Linguistics, 38 (4), 1-25. DOI: 10.1093/applin/amv047.

Sajavaara, K. 2006. Kielivalinnat ja kielten opiskelu. I R. Alanen, H. Dufva \& K. Mäntylä (red.) Kielen päällä: näkökulmia kieleen ja kielenkäyttöön. Jyväskylä: Soveltavan kielentutkimuksen keskus, Jyväskylän yliopisto, 223-254.

Smith, L. E. 1992. Spread of English and issues of intelligibility. I B. B. Kachru (red.) The other tongue: English across cultures. 2. uppl. Urbana (III.): University of Illinois Press, 75-90.

Sturesson, L.-O. 2016. Bruten svenska: brytning och förståelighet i svenskt uttal. Kalmar Växjö: Linne universitet. http://urn.kb.se/resolve?urn=urn\%3Anbn\%3Ase\% 3Alnu\%3Adiva-53464. 
Takala, S. (red.) 1993. Suullinen kielitaito ja sen arviointi. Kasvatustieteiden tutkimuslaitoksen julkaisusarja B: Teoriaa ja käytäntöä 77. Jyväskylä: Kasvatustieteiden tutkimuslaitos.

Tergujeff, E. 2013. English pronunciation teaching in Finland. Jyväskylä Studies in Humanities 207. Jyväskylä: University of Jyväskylä. http://urn.fi/URN:ISBN:978951-39-5322-5.

Thorén, B. 2008. The priority of temporal aspects in L2-Swedish prosody: studies in perception and production. Stockholm: University of Stockholm. http://urn.kb. se/resolve?urn=urn\%3Anbn\%3Ase\%3Asu\%3Adiva-7448.

Tuokko, E. 2002. Perusopetuksen päättövaiheen ruotsin kielen oppimistulosten kansallinen arviointi 2001. Helsinki: Opetushallitus.

Ullakonoja, R. 2011. Da. Eto vopros! Prosodic development of Finnish students' readaloud Russian during study in Russia. Jyväskylä Studies in Humanities 151. Jyväskylä: University of Jyväskylä. http://urn.fi/URN:ISBN:978-951-39-4209-0.

Ullakonoja, R. \& H. Dufva 2016. Toisen ja vieraan kielen ääntämisen oppimisen haasteet. NMI-Bulletin, 26 (2), 4-18.

Wingstedt, M. \& R. Schulman 1984. Comprehension of foreign accents. I W. Dressler (red.) Phonologica 1984: proceedings of the fifth international phonology meeting. New York (N. Y.): Cambridge University Press, 339-344.

Ylioppilastutkintolautakunta 2016. Ylioppilastutkintoon osallistujat kokeittain. https: //www.ylioppilastutkinto.fi/images/sivuston_tiedostot/stat/FB2016KT2001.pdf [hämtad 2016-5-19]. 


\section{Bilaga 1}

Detta är ett röstmeddelande som du ska tala in i din väns telefon. Vännen heter Peter, och meddelandet handlar om hans syster Eva som har råkat ut för en bilolycka, men har inte skadats allvarligt.

Titta igenom texten först, och läs sedan in den på band.

Om du säger / uttalar någonting fel, ingen fara - ta bara om hela meningen!

Hej Peter!

Jag försökte ringa dig, men din mobil var avstängd. Var är du?! Hoppas att du hör mitt meddelande snart. Eva ligger på sjukhus. Hon råkade ut för en bilolycka i morse, men det är ingen fara med henne!

Eva åkte till jobbet med min bil. I den stora korsningen på Vasa-gatan kom en buss som körde för fort och kunde inte stanna vid rödljuset. Som du kanske vet var det kyligt och jättehalt på morgonen. Eva hann inte stoppa sin bil utan körde rakt in i bussen. Hon kände sig yr, hon hade ont i huvudet, ryggen och ena benet. Därför fördes hon till sjukhus.

Till all lycka mår Eva ganska bra nu! Läkaren tror att hon kommer att skrivas ut i övermorgon eller kanske på fredag. Ska vi hälsa på henne på sjukhuset? Hon är i rum nummer 28B, på fjärde våningen. Om du vill så följer jag gärna med. Jag kan visa rummet för dig sedan - det är svårt att hitta på sjukhuset! Min bil är okörbar just nu så det blir du som får skjutsa mig!

Men ring mig när du hör det här meddelandet! 